\title{
A Study on Current Conditions and Soccer Teaching Model for Elementary School Students in Demonstration Schools
}

\author{
Maitree Koonlaboot ${ }^{1,2}$, Noppadon Kongsilp ${ }^{2}$, Anan Malalat ${ }^{3} \&$ Parkpoom Rattanarojanakul ${ }^{4}$ \\ ${ }^{1}$ Ed.D. Candidate, The Graduate School of Health Education and Physical Education Bangkok: Graduate School, \\ Srinakharinwirot University, Thailand \\ ${ }^{2}$ Srinakharinwirot University: Prasarnmit Demonstration School (Elementary), Bangkok, Thailand \\ ${ }^{3}$ Department of Health Education, Faculty of Physical Education, Srinakharinwirot University, Thailand \\ ${ }^{4}$ Department of Physical Education, Faculty of Physical Education, Srinakharinwirot University, Thailand \\ Correspondence: Maitree Koonlaboot, Srinakharinwirot University 114 Sukhumvit 23, Bangkok 10110, Thailand
}

Received: April 10, 2018

Accepted: May 3, 2018

Online Published: May 7, 2018

doi:10.5430/ijhe.v7n3p45

URL: https://doi.org/10.5430/ijhe.v7n3p45

\begin{abstract}
The purpose of this study was to study current conditions and soccer teaching model for elementary school students in the demonstration schools. This study used a qualitative method. Data collection was conducted by interview. Twelve informants involved with soccer instruction were selected by using purposive sampling technique from the demonstration schools. The informants consisted of four instructors, four student guardians, and four elementary school students. The interview result has been described its contents based on interview topics and it clarified descriptive information in three aspects as the followings: 1) As for the current conditions of soccer teaching model for elementary school students in the demonstration schools, the informants had different opinions either it was appropriate or inappropriate, 2) Soccer teaching model for elementary school students in the demonstration schools comprises of four prime aspects: instructor, lesson management, facility, and learners, 3) There are recommendations for further implementations of soccer teaching model for elementary school students in the demonstration schools to apply in the future. The findings from this study are useful for soccer instructors at the elementary school level or for instructors in educational institutes at various levels, including those who are interested in using as a guideline to improve their soccer teaching model in case it is appropriate to their students.
\end{abstract}

Keywords: essential requirement, teaching model, soccer

\section{Introduction}

Currently, soccer in Thailand has been promoted to a professional sport. It is considered an alternative career path for a person who is proficient in soccer. In addition, there are many professional soccer players with different nationalities in Thailand. Therefore, having a decent soccer fundamental skills of youth players would be particularly crucial to develop advanced soccer skills at the national level. In terms of physical education, students are given opportunities to participate in a wide variety of physical activities and sports individually and collectively with their teams. Those activities include Thai and international sports. Physical education arrangement for recreation purpose is important for encouraging students to develop their physical movement skills depending on the types of physical education activities. Moreover, student physical fitness and sport skills could be able to develop beyond what has been provided in the classroom. It is often that physical education class schedule would take place only one hour per week, according to basic learning objectives of most schools, even though the Basic Education Core Curriculum's structure does not require schools to make such a physical education class arrangement. As a result, this program would benefit students to develop more of what they have learned from classes. Schools may organize physical activities for students any time in each day whenever students are free from their other classes. Student development activities could feature in fitness/sport clubs (Ministry of Education, 2008: 6).

At present, Thai youth increasingly realizes the importance of exercises for good health from various activities. The Basic Education Core Curriculum in the field of health education and physical education aims to achieve effective results of human growth and human development. Performing an exercise movement from Thai sports and games or participating in international sports would enhance overall health and physical fitness, promote discipline and respecting rules of students, and increase skills for improving physical and mental health. Physical education 
teaching plan of elementary school level under the Basic Education Core Curriculum B.E. 2551 (2008) is fundamental and compulsory subject to all students in order to generate learning experiences and individual development in terms of knowledge, attitudes, skills, physical fitness, and desirable attributes, especially moral and ethics (Division of Academic and Educational Standards, 2009). Health education and physical education aimed to maintain health, health care, development of the quality of life of the people and the community. Moreover, physical education aims to encourage students to use exercises, games and sports as the tools for overall physical, mental, social and intellectual development. Klinkhom (2016) reported that physical education helps students to show basic movement skills and to control themselves in mixed movement. The findings consistent with Bloom's concept (1971) which states that human behavior consists of three parts: 1) knowledge or multiple intelligences, 2) feelings or affective domain, 3) practice or psychomotor domain.

The researcher was interested in studying and developing a soccer teaching model for elementary school students in the demonstration schools as a guideline for managing soccer instruction. Before getting the new soccer teaching model, the information about the current conditions and a soccer teaching model for elementary school students in the demonstration schools should provide. However, up to now, no information about the current conditions and soccer teaching model for elementary school students in the demonstration schools has been reported. Therefore, the purpose of this study was to study current conditions and soccer teaching model for elementary school students in the demonstration schools. This research is useful for soccer instructors at the elementary school level or for instructors in educational institutes at various levels, including those who are interested in applying this research into practice or using as a guideline to improve their soccer teaching format in case it is appropriate to their students.

\section{Method}

\subsection{Research Informants}

Twelve informants involved with soccer teaching model were interviewed in this study. The informants consisted of four instructors, four student guardians, and four elementary school students. The informants were selected by using purposive sampling technique from the demonstration schools, namely, the Demonstration School of Srinakharinwirot University, the Demonstration School of Kasetsart University, the Demonstration School of Ramkhamhaeng University, and the Demonstration School of Chulalongkorn University. The recruitment was made by choosing informants who involved with soccer teaching model. The characteristics of informants are shown in Table 1.

Table 1. Characteristics of Informants

\begin{tabular}{lccc}
\hline & Female & Male & Age Range (year) \\
\hline Elementary school instructors & & 4 & $35-45$ \\
Elementary school students & - & 4 & $11-12$ \\
Elementary school guardians & 2 & 2 & $35-45$ \\
\hline
\end{tabular}

\subsection{Research Design and Data Collection}

This study used a qualitative method. Data collection was conducted by interviewing the informants. The period of the interview was around 30 to 45 minutes per informant. The interviews were recorded by audiotape. The timeline of the interview was October 16 to November 8, 2016. In order to accomplish the research objective, the interview questions related to a) the current conditions of soccer teaching model for elementary school students in the demonstration schools, b) the compositions of soccer teaching model for elementary school students in the demonstration schools, c) the opinions for further implementations of soccer teaching model for elementary school students in the demonstration schools. Example of questions in an interview were as follows: "What is the current conditions of soccer teaching model in your school?", "Is the teaching style suitable for elementary school students at your school?", "What are the problems and obstacles experienced in soccer teaching at your school?".

\subsection{Procedure}

The steps of the research were as follows: 1) select informants and making an appointment for an interview, 2) conduct interviews with the informants who were chosen to participate in the research, 3) classify and analyze the data, 4) write a summary and report.

\section{Results}

The interview result has been described its contents based on interview topics and it clarified descriptive information in three aspects (Table 2) as the followings: 1) as for the current conditions of soccer teaching model for elementary 
school students in the demonstration schools, the informants had different opinions either it was appropriate or inappropriate, 2) a soccer teaching model for elementary school students in the demonstration schools comprises four prime aspects: instructor, lesson management, facility, and learners, 3) there are opinions for further implementations of soccer teaching model for elementary school students in the demonstration schools to apply in the future.

Table 2. Interview results in three aspects

\begin{tabular}{ll}
\hline \multicolumn{1}{c}{ Interview aspects } & \multicolumn{1}{c}{ Interview results } \\
\hline 1) Current conditions of soccer teaching model & appropriate or inappropriate \\
2) Compositions of soccer teaching model & instructor, lesson management, facility, learners \\
3) Opinions for further implementations of soccer & layout of teaching structure, budgets and expenses, \\
teaching model & preparation before teaching and planned before the class \\
\hline
\end{tabular}

3.1 Current Conditions of Soccer Teaching Model for Elementary School Students in the Demonstration Schools

In terms of the current conditions of soccer teaching model for elementary school students in the demonstration schools, the informants had different opinions either it was appropriate or it was inappropriate as shown in Table 3.

Table 3. Results for the current conditions of soccer teaching model for elementary school students

\begin{tabular}{ll}
\hline \multicolumn{1}{c}{ Appropriate current conditions } & \multicolumn{1}{c}{ Inappropriate current conditions } \\
\hline $\begin{array}{ll}\text { 1) Soccer teaching model encourages students to } \\
\text { develop their preference and interest in soccer }\end{array}$ & 1) Soccer field is smaller than a standard field \\
$\begin{array}{ll}\text { 2) Most soccer instructors have the ability to teach } & \text { 2) Limitation of learning soccer session is the time } \\
\text { soccer } & \text { constraint }\end{array}$ \\
$\begin{array}{ll}\text { 3) Students learn academic lessons in class and practice } & \text { 3) Students' discipline and attributes } \\
\text { in a field after academic study } & \\
\text { 4) Most guardians allow and encourage students to learn } & \\
\text { and practice soccer in their free time }\end{array}$
\end{tabular}

3.1.1 Some informants revealed that conditions of soccer teaching model in the demonstration schools are very well suited because it encourages students who never played soccer to develop their preference and interest in soccer gradually as well as it helps students growing up healthy. The rest of students who already enjoy soccer have stronger preference and interest progressively. Most soccer instructors have the ability to teach soccer. They show various teaching techniques that did not heavily emphasis on academic matters. The teaching content was not neither too difficult nor too easy. Thus, it is appropriate for elementary school students who are not eager to study too much on academic content.

Learning to play soccer starts with lessons from textbooks with image contents that are relevant to practicing soccer skills; for example, passing a football to other players, sending a football with the instep, throwing a football, being a goalkeeper, etc. Students will learn academic lessons in class and practice in a field after academic study. Furthermore, lessons in class have mentioned rules, standards, characters of football sport, and number of players. Even so, those lessons did not include techniques on how to play as a team member, plan to play a football game, as well as how to practice techniques from classroom lessons. It is worth to note that teaching soccer for elementary school students may lead to different outcomes due to the fact that each student has different levels of body fitness, different health conditions and strength that impact students' soccer practice.

Most guardians allowed and encouraged students to learn and practice soccer in their free time. Students have their own interests and prepare themselves to learn and practice soccer. However, some schools have limitations in terms of having a narrow learning space or having a smaller football field than a standard size. As such, they would manage with other approaches; for example, placing soccer class in electives category, providing other appropriate soccer fields near school for practicing, dividing soccer players into a smaller team, and giving an extra soccer class in the evening after school. Teaching soccer with basic lessons may not require large space such as learning football rules is not difficult. However, schools equipped with standard soccer facility would have more advantages from intensive teaching contents; for example, using personal techniques to play football, playing a game with team system, allowing student to practice soccer in the evening after class, etc. Nonetheless, soccer instructors either in well-equipped school or basic-equipped school in terms of facility readiness may train student's physical preparation and movement skills in order to help students getting ready for learning soccer in a more advanced class. 
3.1.2 The informants concerned that conditions of soccer teaching arrangement in the demonstration schools is inappropriate and gave their opinions on that the school area used for training soccer lessons is relatively small or the soccer field is smaller than a standard field. When there are many students practicing at the same time, teachers may not plan their soccer class lessons effectively. Therefore, soccer instructors have to adapt their lesson plans and prepare soccer training session to suit with a number of students. The students may be not familiar with the standard soccer field and they cannot develop their full potentials. In addition, if students have to play soccer in the standard field that they are not familiar with, they may not play a good soccer game as they should be able to. Another limitation is that a learning session is the time constraint. Occasionally, students have to walk together from their classroom to a soccer field. Thus, teachers have less time to give soccer lessons.

In terms of students' discipline and attributes, instructors should focus on combining student's attributes and achievement of learning to make an assessment. Sometimes, soccer athletes in the school may receive lower scores in soccer class than students who have discipline and good attributes. The reason is that students with discipline have a tendency to comply with teachers' instruction and they pay more attention to study in class. Although, such a good student may be incapable of performing a particular soccer skill well, the student illustrates a trait to be a good soccer player with discipline.

\subsection{Compositions of the Soccer Teaching Model for Elementary School Students in the Demonstration Schools}

This research pointed out that soccer teaching model for elementary school students in the demonstration schools should comprise four prime aspects: instructor, lesson management, facility, and learners. Recommendations from this study are shown in Table 4.

Table 4. Results for the compositions of the soccer teaching model for elementary school students

\begin{tabular}{|c|c|}
\hline Compositions of the soccer teaching model & Prime recommendations \\
\hline \multirow[t]{4}{*}{ 1) Instructors } & -Make a tremendous effort to focus on teaching soccer \\
\hline & $\begin{array}{l}\text {-Give importance to train students' discipline during } \\
\text { practice and competition periods }\end{array}$ \\
\hline & $\begin{array}{l}\text {-Have expertise in a wide range of teaching techniques } \\
\text { for every position }\end{array}$ \\
\hline & $\begin{array}{l}\text {-Ensure that students have knowledge as well as an } \\
\text { appreciation of physical exercise and sports. }\end{array}$ \\
\hline \multirow[t]{3}{*}{ 2) Lesson management } & -Improve teaching time \\
\hline & $\begin{array}{l}\text {-Arrange the special skill training for a soccer player in } \\
\text { each position to match each student }\end{array}$ \\
\hline & $\begin{array}{l}\text {-Divide the learning objectives for health improvement } \\
\text { or for competition purpose }\end{array}$ \\
\hline 3) Facility & $\begin{array}{l}\text {-Manage a soccer class in a standard soccer field or at } \\
\text { least having a similar feature to a real competition field }\end{array}$ \\
\hline 4) Learners & $\begin{array}{l}\text {-Focus in class and during the practice period in order to } \\
\text { prevent themselves from being a weakness of the team }\end{array}$ \\
\hline
\end{tabular}

\subsubsection{Instructors}

The instructor should make a tremendous effort to focus on teaching soccer. He/she should be completely dedicated to teach class and start the soccer lessons from basic practice until students are competent enough. Then, the instructor should increase intensive training that is suitable for each student depending on their levels of expertise. This is because each student has different skills. Soccer instructors must have the ability to extract a full potential of students that does not reveal yet, as much as possible. At the same time, instructors need to be able to develop talented students to excel in advanced levels.

Likewise, instructors should give importance to train students' discipline during practicing period and competition period. Some students may not learn to take responsibility and recognize their duty yet. Therefore, it is a role of instructors to build up students' discipline, then teach soccer lessons and how to play in a team.

Soccer instructors should have expertise in a wide range of teaching techniques for every position. Instructors should give a demonstrate to students in order to help them recognize and understand how to play soccer well in different 
positions under their responsibility; for example, goalkeeper position, forward position, midfielder position, or defender position. It includes how to play soccer in various positions such as opening long ball, heading, throwing, replacing the vacant position, knocking, crossing, turning, ball control, passing, receiving, shooting, using both feet, finding a gap for playing position, and other basics in playing soccer.

In addition, instructors should ensure that students have knowledge as well as an appreciation of physical exercise and sports. Teaching skills should be divided by levels of difficulty or easiness that are appropriate to the students' age. Teaching the right basic skills benefits students in that they will be able to take their basic soccer skills to develop further skills continuously. Last, after having a soccer class, students should obtain a good attitude toward the sport that they have learned.

\subsubsection{Lesson Management}

As for class management or teaching model at present, the majority of informants viewed that it is appropriate. Only a few schools should make improvements in the following areas.

3.2.2.1 In terms of time constraint, the teaching time is very limited because a soccer class is an elective subject and it is not included in the school curriculum. However, these schools manage this issue by providing a soccer class after school for students who are interested in learning.

3.2.2.2 Special skill training for a soccer player in each position should be arranged to match each student. Techniques of how to play a game and getting ready to play should be taught in theory in order to help students to understand the basics first. Then, the instructor should provide a field practice after classroom session.

3.2.2.3 Soccer instructors should focus to teach in class. Most elementary schools provide a soccer class for students in Grade 1 to Grade 6. Thus, instructors should put emphasis on practicing soccer skills than teaching theoretical content.

3.2.2.4 Instructors should fully commit to teach. It is recommended that soccer should be taught starting from students in Grade 2 to students in Grade 6 because student in Grade 1 may not fully develop a visual relationship capacity. If they are students in Grade 2, their visual maybe considerably improve.

3.2.2.5 Soccer teaching development should establish teaching models that are appropriate to students' age.

3.2.2.6 Soccer instructors should identify clear objectives of learning lessons and inform students every time they have a soccer class. Learning objectives could be divided for health improvement or for competition purpose. Students themselves should have their own study goals; for example, goals to stimulate intellectual aspect and physical development in order to achieve intellectual growth along with physical growth.

\subsubsection{Facility}

In terms of facility, schools should manage a soccer class in a standard soccer field or at least schools should have a soccer field having a similar feature to a real competition field as much as possible in order to help students to feel familiar with a sport field regardless of the weather in rainy, sunny, or windy condition.

\subsubsection{Learners}

In terms of learners, there were some students who did not pay attention to practice soccer. Thus, students should focus in class and during the practice period in order to prevent themselves from being a weakness of the team.

\subsection{Opinions for Further Implementations of Soccer Teaching Model for Elementary School Students in the Demonstration Schools}

Opinions about applying a soccer teaching model for elementary school students in the demonstration schools into practice are the following comments.

3.3.1 Layout of teaching structure should be organized properly and should include time spending for class lessons either it is a regular class time or an irregular class programmed after school, making a learning calendar or a learning schedule, competition schedules to enhance students' experiences, expenditures to organize activities, training session, competitions, extra classes during weekends, etc.

3.3.2 Budgets and expenses should be sufficient for planned activities. Classroom supply should be kept in an up-to-date conditions and appropriate for students in each grade or each age. Preparations for a soccer class before the actual teaching should be managed including instructors, teacher assistants, teaching materials, facilities, and learners. In case a soccer field in the school has limited space, it may necessary to use outside sport fields. These circumstances may cause burdens of transportation to other locations and safety of the students during traveling. 
Therefore, schools should plan and prepare instructors who assist students, vehicles, supply of equipment for practicing, budget, and asking parents' permission in advance to take students to learn soccer outside their school.

3.3.3 Preparation before teaching should be planned roughly before the class schedule; for example, what instructors wish to teach and learning objectives for each class session. Soccer instructors must prepare everything in advance to be ready for the actual class, such as a soccer field that the class takes place, instructional model, and self-preparation of instructors or coaches. Moreover, instructors should be very competent in soccer, be able to give assignments or home works for students to bring home for more intensive practice.

\section{Discussion}

The results of this study provide the information about the current conditions and a soccer teaching model for elementary school students in the demonstration schools. However, there are additional recommendations to be used in developing the soccer teaching model in the future.

In terms of school executives, they are responsible for providing policy, opportunities, and supports for teaching model. If there are any problems, executives must provide solutions for instructors and students.

In terms of soccer instructors, they are responsible for teaching contents of the subjects in the school, assisting students to understand class lessons as much as possible, adapting personal skills during practice period, being dedicated, making a plan to implement a soccer teaching model, and making a plan to handle any situations or any problems that might reoccur. In case schools need to replace the instructor with a new instructor, teaching methods and class contents should be consistent with the same model so that students will not confuse. If there are any other problems in the current teaching system that it cannot be solved immediately, solutions should be applied in the next class.

In terms of classroom supervision, students may ask questions and raise their topic of interests while the instructor is teaching. If there are too many questions during class, the teaching arrangement may not continue smoothly. This obstacle may diminish classroom session and lead to reduced time to practice soccer. Some mature students may come to class late and it would result in incomplete learning sessions. Schools may expect increasing competency of students. Therefore, instructors must manage time well and organize their teaching model in the way that students will get the most benefits and they are able to develop their potentials as much as possible.

In terms of teaching, teaching should get started from the basics and then training practicing skills in accordance with class contents. When students are able to practice fluently, instructors may move on to the next contents and other skills. After class, instructors may review the first content that they taught. Besides, instructors may organize a real competition in their school so that students will get a chance to have a firsthand experience. However, soccer teaching model might confront with upfront problems and obstacles at any time.

In terms of instruction planning, instructors should plan suitable teaching schedules and activity preparations. Activities in class should be various to keep student interests and make them want to learn. Furthermore, instructors should prepare sufficient teaching equipment and facilities to be ready for classes, and should make an effort to obtain new knowledge and teaching techniques at all times.

\section{Conclusion}

In conclusion, the findings obtained from this research was consistent with the concepts of Joyce and Weil (1996). They stated that the instructor establishes the teaching process for 1) setting the conditions, preparing the situation for the learner to learn, and changing the students' behavior as an assignment from the instructor 2) to be teaching guideline for the instructor to help students gain knowledge, skills, attitudes, thinking, and express the ability to learn to achieve the goal easily and more effective. In addition, we could use the obtained information about the current conditions and a soccer teaching model for elementary school students for further developing a new soccer teaching model for elementary school students in the future. Finally, the findings from this study are useful for soccer instructors at the elementary school level or for instructors in educational institutes at various levels, including those who are interested in using as a guideline to improve their soccer teaching model in case it is appropriate to their students.

\section{Acknowledgements}

The authors are grateful to the Graduate School of Srinakharinwirot University for their support. Thank for the informants who participated in the study. 


\section{References}

Bloom, Benjamin S. (1971). Taxonomy of Education Objective: Handbook 1: Cognitive Domain. New York: David McKay Company Inc.

Division of Academic and Educational Standards, Ministry of Education. (2009). Indicators and Core Subjects in Health Education and Physical Education according to the Basic Education Core Curriculum B.E. 2551 (A.D. 2008). Bangkok: Division of Academic and Educational Standards. Retrieved from http://www.esbuy.net/_files_school/00000957/document/00000957_0_20161101-141213.pdf

Joyce, B.; \& Weil, M. (1996). Models of teaching (5th ed.). London: Allyn and Bacon.

Ministry of Education. (2008). Basic Education Core Curriculum B.E. 2551 (A.D. 2008). Bangkok: The Express Transportation Organization of Thailand Publisher. Retrieved from http://lib.edu.chula.ac.th/FILEROOM/CABCU_PAMPHELT/DRAWER01/GENERAL/DATA0000/00000218.P DF

Phanumas Klinkhom (2016). Development of basic skills for playing soccer using a set of learning activities focusing on practical skills for students in Grade 6. Paper presented at the third National Symposium for Integrated Researches, Use Knowledge to Sustainable Development, Nakhon Ratchasima College, Nakhon Ratchasima, Thailand. Paper retrieved from http://journal.nmc.ac.th/th/admin/Journal/2559Vol4No1_74.pdf 